\title{
RESHAPING THE DANUBE REGION IMAGINARY: A FOCUS ON DIGITAL TRANSFORMATION AND HPC
}

\section{Victor Cepoi}

Faculty of Information Studies, Slovenia

E-mail: victor.cepoi@fis.unm.si

Abstract: In 2010, the European Commission launched Europe 2020 Strategy in response to the economic crisis and boost the EU's economy. Later the same year, the EC proposes the European Union Strategy for Danube Region. The Danube Region being so diverse, it is important to understand it not only from the legal or administrative boundaries, but also to grasp the historical and cultural diversity. Consequently, in order not to neglect these primordial factors, this article addresses the Danube Region as a political and economic imaginary through the lenses of Cultural Political Economy, that focuses on the complexity of the reality. Following this line of argument, the aim is to understand the economic reshape of the Danube Region and the consequences of the European Union Strategy for Danube Region.

Key-words: Cultural Political Economy, Europe 2020, Danube Region, digital transformation, high-performance computing

\section{Introduction}

Being part of a complex and changing environment, determines any region to have adaptive capabilities and rely on dynamin investment in order to survive. Additionally, it is important to mention that regions are not alike, thus there is a difference in "quality" or "efficiency" of the regional systems. Even more, these differences lead to different outcomes of development, though the inputs sometimes are identical in quantitative and qualitative terms.

In the end of 2010, the European Commission elaborates the European Union Strategy for Danube Region (European Commission 2010a). The strategy comes as a response to address the challenges of the economic crisis by reinforcing the efforts to overcome it in a sustainable approach. Thus, the Strategy has the main aim to provide continuous framework policy integration and coherent development of the Danube Region, from the core of economic developed (Germany - Baden - Württemberg and Bavaria) to the 
peripheral region (Moldova and Ukraine). As Besednjak Valić highlights (2019), the Danube Region is a very sensitive group of countries, since it comprises both EU and non-EU member states. Additionally, the group is not heterogenous, because there are most developed regions from Germany and underdeveloped regions from Moldova and Ukraine. Nonetheless, to having different development trajectories, it is adding up to these differences their dissimilarities in culture and economy, which affects the innovation system. This aspect is important, because as Rončević and Makarovič (2011a) show, the socio-cultural field represents an essential element of the environment, because it limits the options of strategic actors Following this line of argument, the re-industrialization of the Danube Region is important, because it has an impact on the economic development of the countries of the Danube (Besednjak Valić 2019,44). As the author points, the digital transformation alongside the usage and applicability of high-performance computing is the path toward re-industrializing the region and helping to shorten the gap between innovation leaders and modest innovators. This argument is especially valid for the parts where the effects of the economic are still noticeable. Thus, by improving certain framework initiatives of the developmental performance of the Danube countries, the industrial base gives a solid starting point and offers possible success.

It is known that the most advanced HPC infrastructure and knowledge are located in well-off western parts of the Danube region. Meanwhile, enterprises from eastern part of the Danube Region have limited access and competencies. Even more, transnational cooperation in the region is limited, which is further hindering innovation and technology transfer (Coscodaru, Modic and Rončević 2019, 8). Thus, this aspect highlights one more time, the need of reshaping the economic reality, in order to redress the existing discrepancies between core and periphery regions. In the context of promotion of new economic initiatives, crises are comprehended as good opportunities to develop or reshape economic imaginaries, because any economic crisis affects the economic identity and performance. Additionally, it creates a cognitive and strategic disorientation and trigger proliferation in interpretations and proposed solutions (Jessop 2010). In the context of the new discourses at the EU level during the switch toward a knowledge-based economy, as Jessop (2004) points, this new type of economy can be regarded as a distinctive semiotic order. As a result, discourses and styles are (re-) articulated around, in this case, a new economic strategy. Nevertheless, it does need necessarily has to be a strategy, but it can also be perceived as a state project which affects diverse institutional orders and the lifeworld. Thus, knowledge-based economy is linked to notions or visions, like the 
information economy, learning economy, creative economy and information society (Sum and Jessop 2015, 270). Nevertheless, as Sum and Jessop point, the official economic strategies (towns, cities and regions through national states and supranational bodies like the European Union) have advanced knowledge-based economy on the global level. Also, it made the knowledgebased economy central to future growth and increase the critical role in longterm competitive advantage and sustained prosperity for new and old industries and services. Even if economies in general can be seen as being knowledge economies, but not all are described and governed, let alone find themselves so labelled in different discourses. As Sum and Jessop (2013) highlight, the economic imaginary identifies, privileges and seeks to stabilize some economic activities from the totality of economic relations. Asa result, these economic relations are transformed into objects of observation, calculation and governance (Sum and Jessop 2013, 16).

The Danube Region being so diverse, it is important to understand it not only from the legal or administrative boundaries, but also to grasp the historical and cultural diversity. The social, economic, and political differences in the period of transition can be explained by historical and cultural background (Adam, Makarovičc, Rončević and Tomšič 2005, 16). Consequently, in order not to neglect these primordial factors, this article addresses the Danube Region as an economic and political imaginary through the lenses of Cultural Political Economy, that focuses on the complexity of the reality. Following this line of argument, the aim is to understand the economic reshape of the Danube Region, and the consequences of the European Union Strategy for Danube Region.

\section{Cultural Political Economy}

The new complex realities concentrate on social, economic and political relations and identities (Paasi 2002). This statement is reinforced with the economic realities after the 2008 crisis, including in the EU. Thus, there was a need to reshape existing economic imaginaries. As Jessop and Oosterlynck point (2008), both history and institutional bodies matter in the perspective of the regional economic institutionalization. Economy through the lenses of Cultural Political Economy has both semiotic (discoursive) and extrasemiotic (aspects). These two coexist and influence each other (Sum and Jessop 2013, 265). As a result, the Cultural Political Economy's role is to contribute in understanding of new regionalism (Makarovič, Šušterič and Rončević 2013). Thus, as Hughes, Sasse and Gordon (2003) point that the EU regional policy promotes institutional building, learning and policy-making 
innovation at regional and local levels. Following this line of argument, incorporating Cultural Political Economy, it has three main distinctive features:

1. For CPE both history and institutions matter;

2. Culture has to be considered, because of its ability to shape the complex relations between meaning and practices. The economic and political conduct is a consequence of the intersubjective meaning;

3. CPE focuses on the co-evolution of semiotic and extra-semiotic processes and their impact on the constitution and dynamic of capitalist formations (Jessop and Oosterlynck 2008, 3).

Jessop $(2010,344)$ emphasizes that "imaginary" is a term for semiotic systems. These imaginaries frame individual experiences of the complex world. Thus, these shapes lived experience in a complex world. Additionally, these experiences consist of specific configuration of genres, discourses and styles. Even more, imagined economies are informally constituted and reproduced on many sites and scales, in different spatio-temporal contexts, and over various spatio-temporal horizons (Jessop 2010, 345). These extend through stable economic organizations, networks, and clusters to 'macroeconomic' regimes. The new economic imaginaries, are not static, but rather develop as economic, political and intellectual forces. These forces can be political parties, think tanks, bodies such as the OECD or World Bank, business associations and trade union, sand social movements.

Imaginaries are on their own, thus create a world where the space of possibility of imaginations and thought is present experience a different reality. As a result, this reality can differ from the real reality (Beckert 2011, $5)$. Nevertheless, in the complexity of the real world of the economic context, these imaginaries motivate actions in the real world, because at a certain stage something imaginary will turn in something existing at a later point in time (Beckert 2011, 11). Also, imaginaries have the property to adapt, but be vulnerable to contradictory experiences in the real world (Wilkinson 1970, 312 ). It is a dynamic process, where the order is created rather than inherited. At the same time, there must be a clear difference between the role of imaginaries and institutions. On one hand, imaginaries are semiotic systems, which have the role providing the foundation for the lived experience of the complex world. On the other hand, institutions embed the lived experience in broader social relations, and interpreting across various social spheres (Jessop and Oosterlynck 2008, 6). As stated earlier, crises are good opportunities to reshape an imaginary. As any other process, it needs certain 
mechanisms through which it triggers the proliferation in interpretations and proposed solutions. CPE emphasizes the integration of three evolutionary mechanisms of variation, selection, and retention into semiotic analysis (Jessop 2010, 341):

- Variation - variation in discourses and practices, where these adapt to specific circumstances, new challenges or crises;

- Selection - of particular discourses as against other available ones, for interpreting events, legitimizing actions and representing social phenomena;

- Retention - of some resonant discourses and inclusion in an actor's habitus, integration into institutional rules, articulation into widely accepted accumulation strategies, state projects etc.

Additionally, Jessop also mentions about a fourth mechanism: reinforcement. It has the aim to also filter out contrary discourses and practices. Relying on discursive and material tools, appropriated genres, styles and strategies are strengthened. Furthermore, it allows to selectively eliminate inappropriate alternatives and to promote complementary discourses across society. As a result, these mechanisms influence the way a new imaginary is created and shaped through the frame of different discourses that actors chose. Thus, as Rončević and Makarovič (2011b) highlighted the role of the semiotic and extra-semiotic factors in strategy formation process through evolutionary mechanisms. The authors showed that the processes of societal steering are inherently social processes and attempted to develop analytical solution that would allow to fully acknowledge nature of these processes. Even more, the process is influenced by a variety of proximate and background social institution, which are also socially constructed and depend on respective social setting. At the same time, strategic steering is not only a simple technocratic process, but rather multilayered and complex social processes (Makarovič and Rončević 2010). As a result, as the authors point, this implies the involvement of both - possibility of strategic steering of development and dealing with some of the key sociological questions. In this context, actors' actions are not only realisation of social trends, but also actors are autonomous in relation to operations of structure to certain extent. 


\section{Danube Region Strategy}

Jessop mentions that in the case of successful economic imaginaries there are present constitutive forces in the social, political, institutional and material world, as for example the "knowledge society" (cited in Makarovič, Šušterič and Rončević 2013, 618). It has become such a powerful political and economic imaginary that it exerts influence in shaping policy paradigms, strategies, and policies in and across many different fields of social practice. At the same time, it is elemental to highlight that it does not exist at a national, let alone quasi- continental (e.g. European) level It is represented at a local or regional level and in certain forms of cross- regional economic spaces (Sum and Jessop 2015, 261).

By "knowledge society" or knowledge-economy, we can understand it as both a strategy and a discourse (Cummings, Regeer, Haan, Zweekhorst and Bunders 2017). As the authors highlight, the discourses that are part of the knowledge society includes and topics relating to ICTs, intellectual property, science, economic development and discourses related to the network society. It can be stated the embracement of a new imaginary regarding the European knowledge economy started with the appearance of a new hegemonic strategy - New Lisbon (Robertson 2007). This strategy can be seen a continuation of the final Communication by the EC tabled in 2003 The Role of the Universities in the Europe of Knowledge (TRUEK). Even more, the concepts such as 'innovation', 'knowledge' and 'education' shifted their meanings from the Lisbon $2000^{1}$ and the TRUEK discourse. As Robertson emphasizes $(2007,7)$ the focus on innovation (particular areas as digital technologies, biotechnology and the environment) can be regarded as a mean to become a knowledge society. Additionally, it shifted from economies as socially embedded to focusing on human capital. For "knowledge", the new discourse highlights its role as research and development to produce value in the marketplace. Additionally, in 2010 the European Commission (2010b) has launched Europe 2020 Strategy in response to the economic crisis and boost

\footnotetext{
${ }^{1}$ Robertson emphasizes $(2005,5)$ that: "the main strategic orientations of Lisbon 2000 were to combine supply side economics with macro-economic and social concerns; to develop information technologies, R\&D policy for institutions, enterprise policy, economic reforms that targeted job creation, macro-economic policies that focused on employment and structural change along with education and training, a renewed social model, new priorities for school-based education, active employment policies focused on lifelong learning, new social protection politics, national plans to reduce social exclusion, and improved social dialogue between European civil society, the economy and structures of government."
} 
the EU's economy. Thus, the strategy proposed three key drivers for growth, to be implemented through concrete actions at EU and national levels: smart growth (fostering knowledge, innovation, education and digital society), sustainable growth (making our production more resource efficient while boosting our competitiveness) and inclusive growth (raising participation in the labour market, the acquisition of skills and the fight against poverty). The Commission proposed an agenda consisting of a series of flagship initiatives. Implementing these initiatives at EU-level organisations, Member States, local and regional authorities' level, focused on the several priorities among which are:

- Innovation union - re-focusing $R \& D$ and innovation policy on major challenges, while closing the gap between science and market to turn inventions into products. As an example, the Community Patent could save companies $289 €$ million each year.

- A digital agenda for Europe - delivering sustainable economic and social benefits from a Digital Single Market based on ultra-fast internet. All Europeans should have access to high speed internet by 2013.

- An industrial policy for green growth - helping the EU's industrial base to be competitive in the post-crisis world, promoting entrepreneurship and developing new skills. This would create millions of new jobs;

- An agenda for new skills and jobs - creating the conditions for modernizing labor markets, with a view to raising employment levels and ensuring the sustainability of our social models, while babyboomers retire;

- European platform against poverty - ensuring economic, social and territorial cohesion by helping the poor and socially excluded and enabling them to play an active part in society (ibid.).

These discourses created a favorable milieu for the adaption toward new trends, thus creating new economic imaginaries within the EU. Following this line of new discourses, in order to address the challenges risen from the appearance of a new knowledge society, the EU Strategy for the Danube Region (EUSDR) encompasses four major pillars in order to address the challenges (EUSDR 2019);

- Connecting the Danube Region (transport, energy, culture and tourism)

- Protecting the Environment in the Danube Region (water, biodiversity and soils) 
- Building Prosperity in the Danube Region (education and skills, research and innovation, enterprises, employment market and marginalized communities)

- Strengthening the Danube Region (institutional capacity and cooperation)

Thus, these four pillars compress 12 priority areas, among which is focused on the Knowledge Society (research, education and ICT). After the revision of the proposed targets (Danube Knowledge Society 2016), the priority area focuses on:

- increasement of the effectiveness of investment in R\&I through establishment of a funding coordination network aiming to initiate a minimum of 2 dedicated EUSDR activities each year (e.g. joint calls; joint strategic project proposals (within a multilateral framework).

- increasement of the number of EPO and PCT patent applications filed from the Danube Region by $20 \%$ by 2020 .

- enhancement regional research and education co-operation to reach $20 \%$ of academic mobility within the region by 2020 .

- increasement of the annual output of co-publications in the region by $15 \%$ by 2020 .

- development of RIS3 in all Danube countries (or their regions) by 2020.

We can consider the proposed targets as one of the variations of the main discourse (the Danube Strategy). Thus, each of this priority area is part of the selection process. Among the big number of priority areas certain have to be retained, consequently integrated into institutional rules and articulated into widely accepted accumulation strategies

It was proven that positive development of success economies is achieved through redefining what will change and how it will be changed. As a result, the systemic discourse is perceived as an effective strategic process in most newly developed economies (Rončević and Fric 2017). As the authors point, in the case of success economies the systemic discourse is developed from the centre of government towards the periphery. As example, it can be highlighted as an example the amount applications that were submitted during the first call of the project. Thus, as the registration opened, EUSDR received 576 submissions from which 547 have been considered for assessment (Interreg Danube Region Programme 2019a). The considered application embraced 5223 institutions from all the Danube region. During 
the second call, there were submitted 119 proposals from which 22 were approved (Interreg Danube Region Programme 2019b).

Figure 1. First call for Danube Transnational Programme

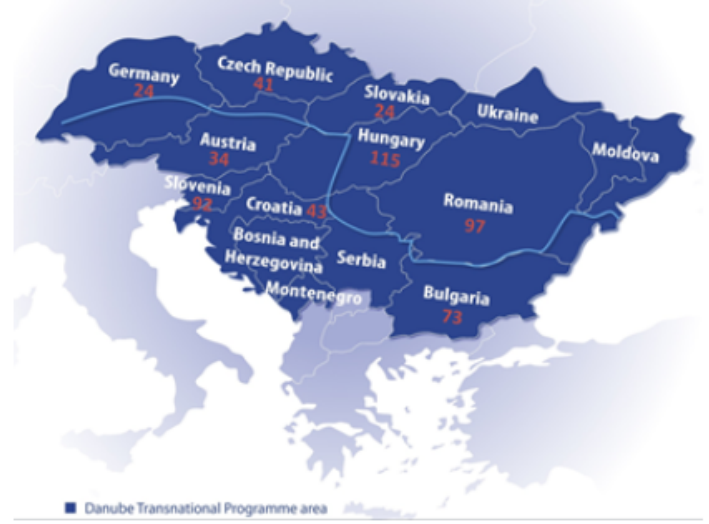

Source: Interreg Danube Region Programme

\subsection{Assessment of the Digital Transformation in the Danube Region}

It is important to highlight the role of the Digital Transformation and the Internet, because these are seen as part of the democratic processes, especially the role in the civil and political processes (Tiscornia and Fernandez-Barrera 2012). Thus, through the framework of the digitization and increasing the access to the internet, societies are able to have a more active role, because the costs of participation are reduced. As Fuchs (2007) points that with the changes in the technological development and in the sphere of information, communication considerably reduces the obstacles to the realization of participatory democracies. Even more, the new digital trends, formulate the basis of participatory democracy relying on electronic democracy, where the area for communication between citizens and the common will formed is seen as a virtual space. Lastly, it is important to highlight that the rise of the information society raises a number of new fields for social scientists to focus (Cepoi 2017). Even more, the development of the knowledge-based economy produces new sub-disciplines and transdisciplines, because the new knowledge is created the reflexive appliance of the knowledge (Jessop 2008). The dynamic that is created, thus creates new problems and/ or solutions. For example, to consider the shift toward 
Industry 4.0 or Digital Transformation, as part of reshaping the economic imaginary with the help of various discoursed that embrace the new complex realities concentrated on social, economic and political relations and identities.

Lasi and Fetke (2014) understand the term "Industry 4.0" as primarily IT driven changes in the manufacturing systems. Additionally, the changes encompass organization implications with the expectations of a change from product- to service-orientation. Thus, as the author highlights, new emerging enterprises will adopt specific roles in the manufacturing process. When it comes to Digital Transformation, the focus is on the changes that digital technologies bring to the industry (Hess, Matt, Benlian and Wiesböck, 2016). As a consequence, this focus results in changing the products or organizational structures. The digital transformation, helps to gain benefits of digital technologies, such as productivity improvements, cost reductions and innovation, thus contributing to business success. As the authors point that no sector or organization is immune to the effects of digital transformation, even if it is a challenge in exploiting new digital technologies. Because of that, it can be stated that digital transformation has become a high priority on leadership agendas.

In the new digital marketplace, businesses are undertaking the digital transformations and rethink what customers value most and create operating models that take advantage of what's newly possible for competitive differentiation (Berman 2012). As the author highlights, the digital transformation takes effect via four levels: digital data, automation, connectivity and digital customer access. With the help of digital data analysis, the industry has a better prediction and decision making. Also, the automation helps in combining traditional technologies with artificial intelligence, which reduces the error rates, adds speed and cuts operating costs. Connectivity shortens the production lead times and innovation cycles. Lastly, Digital Customer Access offers full transparency and new kinds of services by having direct access to customers. Besednjak Valić $(2019,25)$ mentions that the industry sector faces a challenge and opportunity of digitalisation. Thus, there are several key technologies that encompass the processes of digitalisation: Social Media, Mobile Services, Cloud technologies, Internet of Thing (IoT), Cybersecurity solutions, Robotics and automated machinery, Big data and data analytics, 3D printing, and Artificial Intelligence. Some of these are not technologically too demanding, others as Artificial Intelligence, Big Data, and IoT demand the usage of High-Performance Computing - HPC. For that purpose, at the EU level, there is present the Digital Transformation Scoreboard. The aim of the Digital Transformation 
Scoreboard is to monitor the transformation of existing industry and enterprises (High-performance computing for Effective Innovation in the Danube Region 2017). The data is obtained on two levels: firstly, it adopts national indicators to monitor digital transformation in Europe with a geographic focus and from a macro-perspective; secondly it uses qualitative and quantitative data to investigate the adoption of digital technologies across two non-ICT sectors. Nonetheless, it monitors two indexes, first being Digital Technology Integration Index (DTII) and second Digital Transformation Enablers' Index (DTEI).

As the European Commission highlighted in the Report of the Strategic Policy Forum, the digitalization of European manufacturing can contribute to $15 \%$ to $20 \%$ growth by 2030 (in Ștefănigă 2019). Thus, in order to achieve this level of development and considering the challenges in the Danube Region, EUSDR proposed a number of Guidelines for the Digital Transformation.

Table 1. Digital transformation of Industry Guidelines at Danube region level

\begin{tabular}{ll}
\hline Digital transformation of Industry Guidelines at Danube region level \\
\hline EUSDR & PA7: To develop the knowledge society through \\
& research, education and information technologies \\
& PA8: Competitiveness \\
& PA9: To invest in people and skills
\end{tabular}

EUSDR Action Plan
To develop and implement strategies to improve the provision and uptake of Information and Communication Technologies in the Danube Region

- To improve the coverage and penetration of broadband in rural areas

- To support certain parts of society in particular need for targeted ICT policies, such as groups with a low uptake, those excluded from access or others with particular training needs

\section{To draw up internet strategies}

- To increase the availability of internet access

- To protect the freedom of expression on the web

- To protect critical infrastructures.

To use e-content and e-services to improve the efficiency and effectiveness of public and private services 
- To increase the availability of technical infrastructure such as broadband and technical equipment

- To use better the EU Funds for ICT

- To create synergies between the building of energy, transport and telecom networks, in order to reduce the cost of broadband installation

To stimulate the emergence of innovative ideas for products and services and their wide validation in the field of the Information Society, using the concept of Living Labs

- To establish Living Labs through which businesses, universities and public administration jointly develop new products by involving customers/users from very early stages, including design

- To support openness to new research and market developments in a public and people-oriented approach

- To support the development of initiatives to stimulate the creation of new markets, the diffusion of new technologies, enhancement of intellectual property protection and standards and impact assessments of new legislative or regulatory proposals on innovation

To foster cooperation and exchange of knowledge between SMEs, academia and the public sector in areas of competence in the Danube Region

- To promote actions supporting the internationalisation of SMEs and facilitating interdisciplinary cooperation

To improve framework conditions for SMEs in areas where competitive infrastructure is missing

- To construct joined or networked industrial and technological parks, as well as transportation, logistics and exhibition centres

- To support investments in competitive infrastructure for SME, especially in rural and border regions

Source: High-performance computing for Effective Innovation in the Danube Region 2017 
In the new discourse in order to reshape the Danube Region economy, EUSDR identified several key actions:

- To develop and implement strategies to improve the provision and uptake of Information and Communication Technologies in the Danube Region,

- To draw up internet strategies,

- To use e-content and e-services to improve the efficiency and effectiveness of public and private services,

- To stimulate the emergence of innovative ideas for products and services and their wide validation in the field of the Information Society, using the concept of Living Labs,

- To foster cooperation and exchange of knowledge between SMEs, academia and the public sector in areas of competence in the Danube Region,

- To improve framework conditions for SMEs in areas where competitive infrastructure is missing.

Each of the key, as a result can be considered one piece that together form the discourse toward shaping the Danube Region imaginary toward a knowledge society. Thus, the discourses focus on the spread of ICT in the Danube Region. At the same time there is the need of improving the internet strategies. These two contribute to the development of another particularity of the discourse. More specifically, the usage of e-content and e-service, which can improve the efficiency and effectiveness of public and private services. Nevertheless, aspects as stimulation the emergence of innovative ideas, foster cooperation and exchange of knowledge between the Triple Helix model (SMEs, academia and public sector) and improving framework conditions for SMEs are also considered for further development of the new political and economic imaginary in the Danube Region with the help of these actions. All these specific steps, go in hand with the new imaginary regarding the European knowledge (Lisbon 2000), where the aim was to improve innovation and create better conditions for areas as digital technologies. Additionally, we can observe how an already existing imaginary reshaped in a new one, considering the new circumstances that arise. Thus, this allows to remark that imaginaries can always be re-shaped and adapted. As a result, relying on these pillars EUSDR created a new political and economic imaginary. The imaginary was created with the help of this new discourse, which motivates actions between the stakeholders in the real world when the new discourse is retained and reinforced. Additionally, what was once a lived experience of the complex world, this imaginary transformed into concrete 
actions (joint projects, networks, synergies, etc.), where a new order is created. The new imaginary relies on Digital transformation of Industry Guidelines

\subsection{Assessment of HPC in the Danube Region}

The HPC Strategy was adopted by the EU in 2012. Thus, the discourse aimed to optimise national and European investments, addressing the entire HPC ecosystem. (Suklan 2019, p. 48). The HPC strategy is implemented through and Action Plan, which consists of four objectives: 1) build exascale systems, 2 ) access to the supercomputing facilities and services by industry and academia - PRACE, 3) excellence in HPC application delivery and disseminate knowledge to stakeholders, 4) EU's position as a global actor (ibid.). Nevertheless, as the author highlights, it seen as a good opportunity to raise awareness, provide training as well as education and skills development within HPC areas.

As mentioned earlier there are several key technologies that encompass the processes of digitalisation, some of which need the utilisation of HighPerformance Computing (HPC). HPC has to be understood as an emerging general-purpose technology. Because it has the possibility to reduce the product development time and increase the effectiveness of innovations, it improves the framework conditions for innovations. Moreover, the capability to process massive data affects the innovative capacity of companies (Zelkowitz in Coscodaru, Modic and Rončević 2019). Therefore, in the framework of reshaping Europe's economic imaginary, HPC has an important role for Europe's economic growth. In order for Europe to maintain the top position on the innovative competitive worldwide area, HPC is a tool for allows industry and academia to develop world-class products, services and inventions (Ștefănigă 2019, 74). As the author emphasizes, there is a need to provide for a European world-class HPC capability. Even if there are important initiatives in framing discourses oriented toward the development of HPC, European HPC is still fragmented in terms of funding and critical mass applications. Another problem that arises is the inequal capability in building and maintaining such infrastructure across Europe. Thus, the discourses should be oriented toward pooling and rationalizing efforts at the European Union level as well as regional levels, such as inside the Danube region.

In present, at the level of the EU, there is a Joint Undertaking - EuroHPC, formed from:

- the European Union, represented by the Commission; 
- Austria, Belgium, Bulgaria, Croatia, Cyprus, Czech Republic, Denmark, Estonia, Finland, France, Germany, Greece, Hungary, Ireland, Italy, Latvia, Lithuania, Luxembourg, the Netherlands, Norway, Poland, Portugal, Romania, Slovakia, Slovenia, Spain, Sweden, Switzerland and Turkey;

- the European Technology Platform for High-Performance Computing (ETP4HPC) Association and the Big Data Value Association (BDVA) (EuroHPC 2019).

The aim is to deploy in Europe a world-class supercomputing infrastructure and a competitive innovation ecosystem in supercomputing technologies, applications and skills with the help of the EU and participating countries. The reality of the HPC in the EU is that it does not match the computing and data needs of European scientists and industry. Even more, the existing HPC depend on non-European technology and are not in global 10 (ibid.). As a result, the EU promoted a discourse on investing in an ambitious supercomputing infrastructure strategy, which would result EU to become one of the world leaders in supercomputing.

Through the HPC present discourses, these trigger HPC development, which is one of the most important challenges of the Danube Region. One of the challenges, is the underdevelopment and differences the core and periphery regions. These differences arise because of several factors as poor entrepreneurial spirit, and poor technology transfer between academia and the business sector, as well as across the borders inefficient utilization of available resources and differences in innovative capabilities (Coscodaru, Modic and Rončević 2019,8 ). Thus, the discourses that transform into policies and projects at the Danube region focus on the unique cultural and natural heritage of the region. These emphasise on poorly-defined advantages in the least developed parts. As a result, low value added and labour-intensive activities are supported, which contribute even more to underdevelopment, because participating actors are equipped with skills that make them even more likely to migrate (Coscodaru, Modic and Rončević 2019, 12). On the opposite, are the projects promoting HPC development. As the authors stress, these types of projects provide tailor-made and transferable technology and skills necessary for knowledge-intensive and high value-added entrepreneurial activities. An eloquent example of how the discourses on reshaping the imaginary and their reinforcement, are the appearance of project as the High-performance computing for Effective Innovation in the Danube Region (InnoHPC). One of the results was the Regional HPC capacity report with detailed and systematic assessment of competencies and 
opportunities of HPC applications for the electronic and automotive industry and assessment of awareness and entrepreneurial spirit of academic institutions (High-performance computing for Effective Innovation in the Danube Region 2017). Thus, the report provided an overview on:

- general appraisal of situation, availability of HPC hard infrastructure and soft competencies, including experience, thematic focus, available infrastructure etc.,

- applications of HPC in the industry R\&D (good practices, level of technological development),

- cooperation between academia and industry (appraisal of situation, good practices, applications of HPC),

- $\quad$ other country-specific relevant aspects, references \& data sources.

- data on HPC capacities in the Danube region in five different themes that are relevant for the whole innovation ecosystem: overview of HPC and innovation profile, institutions, networks, cognitive frames and providers needs.

As the result, the project can be regarded as a revolutionary effort to improve the framework conditions for innovation by providing unique institutional and technological infrastructure, designed specifically to pool and exploit HPC infrastructure on a transnational level. Going in hand in hand with the discourses about knowledge society, the project is one of the means through which the reshaping of the imaginary is possible. InnoHPC is a platform for transnational co-creation and technology transfer without the need for extensive investments in expensive hardware infrastructure in all parts of the Danube region (High-performance computing for Effective Innovation in the Danube Region 2017). Additionally, in line with the discourses on triple helix collaboration in the new imaginary, the project created a transnational cooperation in the Danube region, connecting enterprises, HPC providers (HEIs and RIs), national and regional policymakers and business support. Thus, as stated this approach is in line with the new discourse on HPC and reshaping the imaginary. This is a success story among many others that contribute to the development of the Danube Region and the reshaping of the imaginary. Considering the available existent HPC technology it can improve the conditions for innovation in the Danube Region if all stakeholders carefully apply it and disseminate for a wider range of public (Coscodaru, Modic and Rončević 2019, 15). Also, it is important as the authors point, to connect providers, business and innovation support organizations, higher education and research institutions and policy-makers on a transnational level. Nevertheless, it is important to point that the 
implementation of projects in the Danube Region can be considered as part of the reinforcement mechanism of the main discourse (Europe 2020 strategy).

\section{Conclusions}

The complex discourses that appeared at the EU level during and after the economic crisis, generated a number of processes that the society had to embrace and understand. As Jessop pointed (2004), the new discourses had the aim to switch toward the creation of a knowledge-based economy which is a distinctive semiotic order. One of this process is the creation of new economic imaginaries that lead to the creation of a knowledge society. For the economic imaginary it is not compulsory to have only one discourse. These imaginaries can adapt, but are vulnerable in case of contradictory experiences in the real world. The complexity of the real world determines these realities to have a variation of discourses which compete between them. As a result, there are selected some of them, which are responsible for later actions. Once the discourses are selected, stakeholders and other actors retain these discourses through the articulation into widely accepted accumulation strategies or state projects (for example Europe 2020 and later Danube Region Strategy for the EU). Once these strategies have been retained, the goal is to filter out contrary discourses and practices that are rivaling the created new imaginary.

This article had the aim to show how Cultural Political Economy can be adopted toward the explanation of various imaginaries, in particular with a focus on the Danube Region and its path toward knowledge society. With the help of its mechanisms (variation, selection, retention) the process of economic imaginary creation can be traced and the complex changes can be explained. As emphasized earlier, the new imaginary of the Danube Region was created in the framework of Europe 2020 strategy. Within the analysis with the help of two specific ramifications of the main discourse (Digital Transformation and High-Performance Computing) it was exemplified how the co-evolution of semiotic and extra-semiotic processes impact the constitution and dynamic of reshaping a new economic imaginary. It was highlighted how the initial discourse of the Danube Region Strategy pinpointed the path of reshaping the economic imaginary in the Danube Region. Thus, on one hand the Digital Transformation background created the necessary semiotic conditions for implementation of the Strategy. On the other hand, the framework of High-Performance Computing is a new economic initiative through which the region changes its economic imaginary. Following these trends, it is to upmost importance to understand that 
imaginaries will be in constant change, because of the appearance of new discourses in response to new challenges. Additionally, it is more than expected that after the end of Europe 2020 strategy, we will encounter new discourses that will reshape the created economic imaginary in the Danube Region and in Europe.

\section{References}

Adam, Frane, Makarovič Matej, Rončević Borut And Tomšič, Matevž. 2005. The Challenges Of Sustained Development: The Role Of Socio-Cultural Factors in East-Central Europe. New York; Budapest: Central European University Press, Cop.

Beckert, Jens. 2011. "Imagined futures: Fictional expectations in the economy." Theory \& Society. Forthcoming.

Berman, S.J. 2012. "Digital Transformation: Opportunities to Create New Business Models." Strategy \& Leadership 40, 16-24.

Doi: $10.1108 / 10878571211209314$.

Besednjak Valič, Tamara. 2019. "Innovation, Digitalisation, and the HPC in the Danube Region." In Go With The Flow: High Performance Computing And Innovations in The Danube Region, edited by Borut Roncevic, Raluca Coscodaru and Urska Fric. Vega Press.

Cepoi, Victor. 2017. "Trust and Participation in the Information Society: New and Traditional Information Source." In Trust and Participation in Information Society: new and traditional information sources, edited by Borut Rončević and Matevz Tomšič. Peter Lang.

Coscodaru, Raluca, Modic Dolores and Borut Rončević. 2019. "HighPerformance Computing as a Tool of Transnational Innovation Policy." In Go With The Flow: High Performance Computing And Innovations In The Danube Region, edited by Borut Roncevic, Raluca Coscodaru and Urska Fric. Vega Press

Cummings, Sarah, Regeer Barbara, de Haan Leah and Bunders Joske. 2017."Critical discourse analysis of perspectives on knowledge and the knowledge society within the Sustainable Development Goals". Development Policy Review 36 (6): 727-742. https://doi.org/10.1111/dpr.12296. 
Danube Knowledge Society. 2016. Available at:

https://www.danubeknowledgesociety.eu/priority-area-7.

Accessed April 6, 2019.

EuroHPC. 2019. Available at https://eurohpc-ju.europa.eu/index.html. Accessed April 6, 2019.

European Commision. 2010b. E U R O P E 202 0. A European strategy for smart, sustainable and inclusive growth. Available at https://ec.europa.eu/eu2020/pdf/COMPLET\%20EN\%20BARROSO\%20\%2 0\%20007\%20-\%20Europe\%202020\%20-\%20EN\%20version.pdf. Accessed Accessed April 6, 2019.

European Commission. 2010a. European Union Strategy for Danube Region. https://eur-lex.europa.eu/legalcontent/EN/ALL/?uri=CELEX:52010DC0715. Accessed April 9, 2019.

EUSDR. 2019. Available at https://www.danube-region.eu/. Accessed Accessed April 8, 2019.

Fuchs, Christian. 2007. Internet and Society: Social Theory in the Information Age. Routledge.

Hess, Thosmass, Matt Christian, Benlian Alexander and Wiesböck Florian. 2016. "Options for Formulating a Digital Transformation Strategy." MIS Quarterly Executive 15 (2): 123-139.

High-performance computing for Effective Innovation in the Danube Region. 2017. Digital transformation of Industry Guidelines at Danube region level.

Hughes, James, Sasse Gwendolyn and Gordon Claire. 2003. EU Enlargement and Power Asymmetries: Conditionality and the Commission's Role in Regionalistation in Central and Eastern Europe. Working Paper.

Interreg Danube Region Programme 2019b. Available at http://www.interreg-danube.eu/calls/calls-for-proposals/second-call-forproposals. Accessed April 6, 2019. 
Interreg Danube Region Programme. 2019a. Available at http://www.interreg-danube.eu/news-and-events/programme-news-andevents/109. Accessed April 6, 2019.

Jessop, Bob and Oosterlynck Stjn. 2008. "Cultural Political Economy: On Making the Cultural Turn without Falling into Soft Economic Sociology." Geoforum 39 (3): 1155-1169. Doi: 10.1016/j.geoforum.2006.12.008.

Jessop, Bob. 2004. "Critical Semiotic Analysis and Cultural Political Economy". Critical Discourse Studies 1 (1): 1-16.

Jessop, Bob. 2010. "Cultural political economy and critical policy studies" Critical Policy Studies 3 (3-4): 336-356. Doi: 10.1080/19460171003619741.

Lasi, Heiner and Fettke Peter. 2014. "Industry 4.0." Business \& Information Systems Engineering 6 (4): 239-242.

Makarovič, Matej and Rončević Borut. 2010. "Strategic Processes As Social Processes." Research In social change 3 (2): 85-116.

Makarovič,Matej, Šušterič Janez and Rončević Borut. 2013. "Is Europe 2020 Set to Fail? The Cultural Political Economy of the EU Grand Strategies." European Planning Studies 22 (3): 610-626.

Doi: 10.1080/09654313.2013.782387.

Ngai-Sum, Lin and Jessop Bob. 2013. Towards a Cultural Political Economy: Putting Culture in Its Place in Political Economy. Edward Elgar Pub.

Paasi, Anssi. 2002. "Place and region: regional worlds and words." Progress in Human Geography 26 (6): 802-811.

https://doi.org/10.1191/0309132502ph404pr

Robertson , Susan L. 2007. "Embracing the Global: Crisis and the Creation of a New Semiotic Order to Secure Europe's Knowledge-Based Economy." Education and the Knowledge-Based Economy in Europe Netherlands: Sense Publishers.

Rončević, Borut and Makarovič, Matej. 2010. "Towards The Strategies Of Modern Societies: Systems and social processes." Innovation: the European journal of social science research 23 (3): 223-239a. 
Rončević, Borut and Makarovič, Matej. "Societal Steering In Theoretical Perspective: Social becoming as an analytical solution." Polish Sociological Review 176 (4): 461-472

Rončević, Borut and Fric Urška. 2017. "Path-creation in the Information Society." In Trust and Participation in Information Society: new and traditional information sources, edited by Borut Rončević and Matevz Tomšič. Peter Lang.

Ștefănigă, Sebastian. 2019. "Transnational HPC Infrastructure in the Danube Region." In Go With The Flow: High Performance Computing And Innovations In The Danube Region, edited by Borut Roncevic, Raluca Coscodaru and Urska Fric. Vega Press

Suklan, Jana. 2019. "Gap Analysis: HPC Supply and Demand." In Go With The Flow: High Performance Computing And Innovations In The Danube Region, edited by Borut Roncevic, Raluca Coscodaru and Urska Fric. Vega Press

Tiscornia, Daniela and Fernandez-Barrera Meritxell. 2012. "Knowing the Law as a Prerequisite to Participative eGovernment: The Role of Semantic Technologies." Empowering Open and Collaborative Governance, 119-138

Wilkinson, Kate. 1970. "Phases and roles in community action." Rural Sociology 35 (1): 54-68. 